\title{
The market for a community rehabilitation service
}

\author{
M.T. Spurrell and C.S. Thomas
}

\begin{abstract}
Filty-two mental health workers in South Manchester were asked to complete a survey to tiry to identify patients with chronic mental health problems who would benefit from home-based rehabilttation. These patients were known to the services but were unwilling to attend acttutties in the day hospltal or day centre or come into hospltal for in-patient rehabilitation. Seventy per cent of the mental heatth workers who comprised psychiatisists, social workers and community poychlatric nurses completed the survey. Overall 68 patients were identtiled. Negative symptoms or defect state were the most frequently reported problems with cilliculties with engaging or poor compliance being the next most frequently reported problem. There were some differences in the ranking of the order of problems by different professional groups.
\end{abstract}

In the present setting of increasing demands for limited resources, developments in psychiatric services require to be viewed in terms of their utility as well as any intrinsic merit. Criticisms of some community service developments have included concern that resources have moved away from the population with chronic, disabling mental illness such as schizophrenia (Woof et al, 1988a; 1988b; Bachrach, 1991). In this context, it is important to adequately define a target population in order to design appropriate service delivery.

\section{The study}

This study surveyed the needs of sufferers of chronic mental illness as perceived by experienced mental health workers. The aim was to establish an estimate of the likely market for a formal community (home-based) rehabilitation service for patients suffering from chronic mental illness.

Twenty-one doctors (ten SHO/registrars, four senior registrars and seven consultants), eight social workers and seven community psychiatric nurses (CPNs) who worked in the department of psychiatry of South Manchester and six members of a multidisciplinary community psychiatric team (Pathways Team) were surveyed. The catchment population for the district was around 180,000 .
Each mental health worker was sent a letter and an accompanying form to complete. The letter requested colleagues to identify patients under their care who might benefit from a community rehabilitation service, who had not previously engaged in hospital based or social services programmes. They were asked to focus on adult patients (16-65) with chronic mental illness (e.g. schizophrenia, manic-depressive illness) who were not able or willing to attend a day hospital or day centre. Disorders that were primarily dementias or drug/alcohol related were excluded. Current in-patients were not included. Respondents were also asked to identify particular problem areas of patients.

\section{Findings}

All six members of the Pathways Community Team, all seven CPNs, five out of the eight social workers and 11 out of 21 medical staff replied to the survey. Only two out of ten SHO/registrars responded; but all of the consultants and senior registrars responded, either jointly or individually.

There were 13, 14, 15 and 29 cases identified by the Pathways Team. CPNs, psychiatrists and social workers respectively (Table 1). Only three cases were commonly identified by more than one group of mental health workers. Therefore the total number of cases that the combined professional groups designated as appropriate for consideration for community rehabilitation was 68.

The mean age was 39 (range 20-63), men were more common than women (2:1). The preponderance of men was true for all groups' cases except for those of social workers where the sex ratio was almost equal. Eighty-five per cent of cases had schizophrenic illnesses, $6 \%$ schizo-affective, $4 \%$ bipolar and $4 \%$ other disorders.

In terms of identified problem areas, 'negative symptoms' or 'defect states' were most frequently recorded (60\% of patients). Difficulties with engaging or poor compliance with treatment was the next most frequently reported problem (50\% of patients). After that, more specific functional deficits were reported, such as problem 
Table 1. Patients likely to benefit from a community rehabilitation service, according to different professional groups

\begin{tabular}{llllll}
\hline & $\begin{array}{l}\text { Social } \\
\text { workers }\end{array}$ & Psychiatrists & CPNs & Pathways & Total' \\
\hline Number & 29 & 15 & 14 & 13 & 68 \\
Sex: & 14 & 14 & 9 & 8 & 42 \\
$\quad$ male & 15 & 1 & 5 & 5 & 26 \\
Memale & 40 & 36 & 42 & 39 & 39 \\
Age rage & $23-60$ & $22-59$ & $20-63$ & $25-61$ & $20-63$ \\
Chronic schizophrenia & 26 & 12 & 12 & 11 & 58 \\
Bipolar illness & 1 & 0 & 1 & 1 & 3 \\
Schizo-affective' & 0 & 2 & 1 & 1 & 4 \\
Other & 1 & 2 & 0 & 0 & 3 \\
\hline
\end{tabular}

1. Total numbers exclude the three cases duplicated by a second worker.

with motivation (33\%) and basic living skills (33\%).

Social network problems (usually intra-family conflict), chronic psychosis and social isolation also seemed to be particularly prominent (each reported for about 30\% of patients). There were some differences between the professional groups in the order of prominence of these problems. Socialisation and problems with social network were reported frequently by social workers: problems with motivation were rated highly by psychiatrists and living skills difficulties were prominent among patients seen by CPNs.

\section{Comment}

This survey which requested information on patients in the community who were considered to be in need of home-based rehabilitation was completed by $70 \%$ of mental health workers. Sixty-eight patients who suffered from chronic mental illness who were unable or not willing to attend a day hospital or day centre were identified. This was predominantly a male population. This figure is likely to be an under-estimate as $30 \%$ of mental health workers did not reply, patients in hospital at the time of the survey were not considered and the recall of suitable patients by mental health workers may be incomplete. In addition, there are unknown numbers of subjects among the homeless and in prisons who never use hospital services but are mentally ill.

Only three cases were common between the different mental health workers, suggesting they were relating to different subpopulations of patients. Further, while defect state and compliance or engagement were recorded with almost equal frequency among the different groups, the documentation of other reported problems did vary between professional groups.

The value of such a survey is that it informs mental health planners of the needs of a definite number of patients suffering from chronic mental illness who do not use conventional services, as perceived by the different groups of likely referrers. Furthermore, without this survey no single professional group would have had the perspective to appreciate the size of this patient group. This fact raises the question as to whether a still larger group of sufferers exists in the community.

This particular survey will form a useful starting point for a new experimental homebased rehabilitation team, identifying certain types of patients to be targeted and focusing care on specific problem areas.

\section{References}

BACHRACH, L.L. (1991) Community mental health centers in the USA. In Community Psychiatry (eds D.H. Bennett \& H.L. Freeman). London: Churchill Livingstone.

WOOF K., GoldBERG, D.P. \& FrYERS. T. (1988a) The practice of community psychiatric nursing and mental health social workers in Salford. Some implications for community care. British Journal of Psychiatry, 152, 783-792.

$-\&-(1988 b)$ Further observations on the practice of community care in Salford: differences between community psychiatric nurses and mental health social workers. Brttish Journal of Psychiatry, 153, 30-37.

*M. T. Spurrell, Senior Registrar in Psychiatry; and C. S. Thomas, Consultant Psychiatrist, Department of Psychiatry. Withington Hospital, Manchester M20 8LR

\section{*Correspondence}

